\title{
Acute administration of acyl, but not desacyl ghrelin, decreases blood pressure in healthy humans
}

\author{
Cecilia J Zhang ${ }^{2}$, Martin Bidlingmaier ${ }^{3}$, Mekibib Altaye $^{4}$, Laura C Page ${ }^{5}$, \\ David D'Alessio ${ }^{1,2,6}$, Matthias H Tschöp ${ }^{1,7}$ and Jenny Tong ${ }^{1,2}$
}

${ }^{1}$ Division of Endocrinology, Diabetes and Metabolism, Department of Medicine, University of Cincinnati, Cincinnati, Ohio, USA, 2Division of Endocrinology, Metabolism and Nutrition, Department of Medicine, Duke University, Durham, North Carolina, USA, ${ }^{3}$ Medizinische Klinik und Poliklinik IV, Ludwig-Maximilians-Universität, Munich, Germany, ${ }^{3}$ Biostatistics, Clinical Translational Research Center, Cincinnati Children's Hospital Medical Center, Cincinnati, Ohio, USA, ${ }^{5}$ Division of Pediatric Endocrinology and Diabetes, Department of Pediatrics, Duke University, Durham, North Carolina, USA, ${ }^{6}$ Cincinnati Veterans Affairs Medical Center, Cincinnati, Ohio, USA, and ${ }^{7}$ Institute for Obesity and Diabetes, Helmholtz Diabetes Center Munich and Division of Metabolic Diseases,

Technical University, Munich, Germany

\author{
Correspondence \\ should be addressed \\ to J Tong \\ Email \\ jenny.tong@duke.edu
}

\begin{abstract}
Objective: To compare the effects of acyl ghrelin (AG) and desacyl ghrelin (DAG) on blood pressure (BP), heart rate (HR) and other autonomic parameters in healthy humans and to elucidate the hormonal mechanisms through which AG could exert its cardiovascular effects.

Design: Seventeen healthy participants underwent frequent monitoring of systolic (sBP) and diastolic blood pressure $(\mathrm{dBP}), \mathrm{HR}$, respiratory rate (RR) and body surface temperature (Temp) during continuous infusion of $A G, D A G$, combined AG + DAG or saline control before and during an IV glucose tolerance test on 4 separate days. Plasma catecholamines, renin and aldosterone levels were also measured. Differences in outcome measures between treatment groups were assessed using mixed-model analysis.

Results: Compared to the saline control, AG and combined AG + DAG infusions decreased sBP, dBP, mean arterial blood pressure (MAP), HR and Temp. In contrast, DAG infusion did not alter BP, RR or Temp, but did decrease HR. The AG and $A G+D A G$ infusions also raised plasma aldosterone levels compared to saline $(P<0.001)$ without affecting renin or catecholamine levels.

Conclusions: The decrease in BP, HR, RR and Temp with AG infusion suggests mediation through the autonomic nervous system. The lack of response to DAG suggests that these autonomic effects require activation of the ghrelin receptor.

European Journal of Endocrinology

(2017) 176, 123-132
\end{abstract}

\section{Introduction}

Ghrelin is an orexigenic peptide, synthesized primarily in the stomach (1), which is involved in multiple physiologic functions including growth hormone secretion, energy balance, glucose homeostasis and cardiovascular (CV) regulation (2). After translation but prior to secretion, intracellular ghrelin is acylated at the serine-3 residue by ghrelin $O$-acyltransferase (GOAT). Both acyl (AG) and desacyl ghrelin (DAG) are released into the circulation, and under most physiologic
() 2017 European Society of Endocrinology Printed in Great Britain settings, DAG is the more abundant of the two isoforms (3). Acylation is required for binding and activation of the growth hormone secretagogue receptor type 1a (GHSR1a), the only known receptor for ghrelin. Therefore, most of the biologic actions attributed to ghrelin are considered to be mediated by AG.

AG rises prior to meals and falls after eating with levels varying 2- to 3 -fold between the fasting and fed states (4). As it promotes hunger and feeding behavior,

Published by Bioscientifica Ltd. 
AG has been used in clinical trials as therapy for disease states associated with cachexia $(5,6)$. When given as a continuous infusion, AG also worsens insulin secretion, glucose tolerance and insulin sensitivity ( 7 , 8 ), which is perhaps a protective mechanism against fasting hypoglycemia. Therefore, AG antagonists have been proposed as potential treatments for obesity and type 2 diabetes, although they have only been studied in preclinical trials to date (9). DAG is proposed to have potential beneficial effects on glucose tolerance in rodents (10), which has not been consistently duplicated in humans $(11,12)$. Despite this variability, clinical trials with DAG analogues are ongoing (13).

Recent studies also implicate a role for AG in CV function and blood pressure (BP) control, which has been highlighted in a recent review (14). The GHSR1a is expressed in the myocardium, aorta, coronary arteries, peripheral vasculature and regions of the central nervous system (CNS) involved in CV regulation including spinal cord, brainstem and midbrain autonomic preganglionic neurons $(15,16)$. GOAT is similarly widely expressed in human tissues including the myocardium (17). In healthy humans and those with chronic heart failure, acute ghrelin administration decreases systemic vascular resistance, whereas it increases cardiac output and stroke volume index $(18,19)$. In vitro, AG has direct vasodilatory effects in humans and animals through nitric oxide-dependent and -independent mechanisms
$(15,20,21)$. AG administered centrally also decreases blood pressure in rodents, possibly through suppression of sympathetic activity (22).

As noted previously, emerging evidence suggests that DAG may have physiologic effects that oppose AG and are independent of GHSR1a signaling (23). Similar to AG, DAG can exert endothelial-dependent and -independent vasodilatory effects on human and rodent vasculature in vitro $(15,24)$. In humans, lower levels of DAG are correlated with hypertension (25) and increased cardiovascular risk (26), but the direct effect of DAG on the human CV system has not been investigated prior to this study. Here, we compare the effects of $A G$ and DAG infusions on BP and other autonomic parameters in healthy humans. We include a coadministration $(\mathrm{AG}+\mathrm{DAG})$ treatment arm to determine if DAG potentiates or antagonizes the effects of AG on the CV system. We also evaluate the effect of AG on various BP-modulating hormones to determine the mechanisms by which AG may potentiate its CV actions.

\section{Subjects and methods}

\section{Subjects}

Healthy participants between the ages of 18 and 45 years with a BMI between 18 and $29 \mathrm{~kg} / \mathrm{m}^{2}$ were recruited from
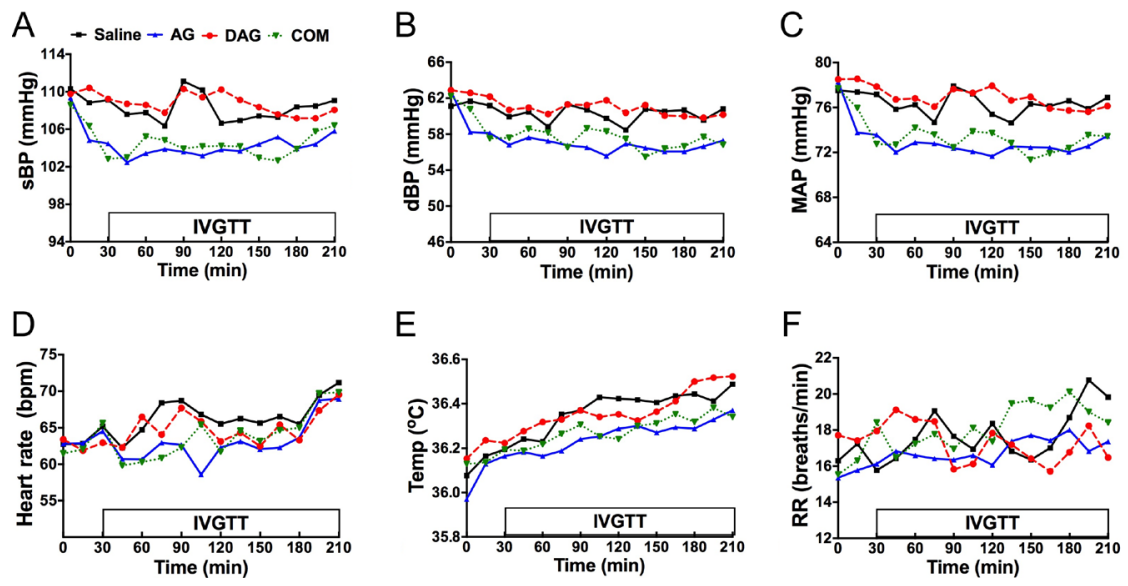

\section{Figure 1}

Blood pressure, heart rate and respiratory rate responses to drug infusion. Systolic blood pressure (sBP; Fig. 1A), diastolic blood pressure (dBP; Fig. 1B), mean arterial pressure (MAP; Fig. 1C), heart rate (HR; Fig. 1D), body surface temperature (Temp; Fig. 1E) and respiratory rate (RR; Fig. 1F) values during acyl ghrelin (AG; $1 \mu \mathrm{g} / \mathrm{kg} / \mathrm{h}$ ), desacyl ghrelin (DAG; $4 \mu \mathrm{g} / \mathrm{kg} / \mathrm{h})$, combined (COM) AG $(1 \mu \mathrm{g} / \mathrm{kg} / \mathrm{h})$ and DAG $(4 \mu \mathrm{g} / \mathrm{kg} / \mathrm{h})$ or saline infusions between 0 and $210 \mathrm{~min}$ in healthy men and women. An intravenous glucose tolerance test (IVGTT) was administered between 30 and $210 \mathrm{~min}$ after the peptide infusions began. Blood pressure is presented in $\mathrm{mmHg}$, heart rate as beats per minute (bpm), Temp as ${ }^{\circ} \mathrm{C}$ and RR as breaths per minute (breaths/min). 
the greater Cincinnati area to participate in a study of the effect of ghrelin on glucose tolerance (11). The data presented here were obtained contemporaneously during this study. Subjects with a history of impaired fasting glucose or diabetes mellitus, recent myocardial infarction, congestive heart failure, active liver or kidney disease, growth hormone deficiency or excess, neuroendocrine tumor, anemia or who were on medications known to alter insulin sensitivity were excluded. Women were studied during their follicular phase.

Study procedures were conducted at the Clinical and Translational Research Center (CTRC) at Cincinnati Children's Hospital Medical Center. Study participants provided written informed consent for the study by signing a form approved by University of Cincinnati and Cincinnati Children's Hospital Medical Center Institutional
Review Boards, and all data collected and reported here are in compliance with the Declaration of Helsinki.

\section{Experimental protocol}

Subjects arrived at the CTRC between 07:30 and 08:00 after a 10- to 12-h fast on four occasions separated by at least five days. IV catheters were placed in veins of both forearms for blood sampling and infusion of test substances. The arm with the sampling catheter was placed in a $55^{\circ} \mathrm{C}$ chamber to arterialize venous blood. $\mathrm{BP}, \mathrm{HR}, \mathrm{RR}$ and Temp were monitored every $15 \mathrm{~min}$ using GE Dash 4000 vital sign monitors during the study procedure. Mean arterial blood pressure (MAP) was calculated using the equation $\mathrm{MAP}=2 / 3$ diastolic $\mathrm{BP}-1 / 3$ systolic BP.

Table 1 Comparison of hemodynamic and autonomic parameters in response to AG and DAG.

\begin{tabular}{|c|c|c|}
\hline & Treatment & Comparison \\
\hline \multirow[t]{6}{*}{ Systolic BP } & AG & Saline \\
\hline & & DAG \\
\hline & & Com \\
\hline & Com & Saline \\
\hline & & DAG \\
\hline & DAG & Saline \\
\hline \multirow[t]{6}{*}{ Diastolic BP } & AG & Saline \\
\hline & & DAG \\
\hline & & Com \\
\hline & Com & Saline \\
\hline & & DAG \\
\hline & DAG & Saline \\
\hline \multirow[t]{6}{*}{ MAP } & AG & Saline \\
\hline & & DAG \\
\hline & & Com \\
\hline & Com & Saline \\
\hline & & DAG \\
\hline & DAG & Saline \\
\hline \multirow[t]{6}{*}{ HR } & AG & Saline \\
\hline & & DAG \\
\hline & & Com \\
\hline & Com & Saline \\
\hline & & DAG \\
\hline & DAG & Saline \\
\hline \multirow[t]{6}{*}{ Temp } & AG & Saline \\
\hline & & DAG \\
\hline & & Com \\
\hline & Com & Saline \\
\hline & & DAG \\
\hline & DAG & Saline \\
\hline \multirow[t]{6}{*}{ RR } & AG & Saline \\
\hline & & DAG \\
\hline & & Com \\
\hline & Com & Saline \\
\hline & & DAG \\
\hline & DAG & Saline \\
\hline
\end{tabular}

\begin{tabular}{|c|c|c|}
\hline$\Delta$ LSM & S.E.M. & DF \\
\hline-3.84 & 0.54 & 48 \\
\hline-4.29 & 0.54 & 48 \\
\hline-0.11 & 0.54 & 48 \\
\hline-3.73 & 0.54 & 48 \\
\hline-4.18 & 0.54 & 48 \\
\hline 0.45 & 0.54 & 48 \\
\hline-3.1 & 0.38 & 48 \\
\hline-3.76 & 0.38 & 48 \\
\hline-0.66 & 0.38 & 48 \\
\hline-2.44 & 0.38 & 48 \\
\hline-3.1 & 0.38 & 48 \\
\hline 0.66 & 0.38 & 48 \\
\hline-3.35 & 0.38 & 48 \\
\hline-3.94 & 0.38 & 48 \\
\hline-0.49 & 0.38 & 48 \\
\hline-2.86 & 0.38 & 48 \\
\hline-3.45 & 0.38 & 48 \\
\hline 0.59 & 0.38 & 48 \\
\hline-3 & 0.59 & 48 \\
\hline-1.56 & 0.59 & 48 \\
\hline-0.67 & 0.59 & 48 \\
\hline-2.33 & 0.59 & 48 \\
\hline-0.89 & 0.59 & 48 \\
\hline-1.44 & 0.59 & 48 \\
\hline-0.11 & 0.03 & 48 \\
\hline-0.12 & 0.03 & 48 \\
\hline-0.03 & 0.03 & 48 \\
\hline-0.08 & 0.03 & 48 \\
\hline-0.09 & 0.03 & 48 \\
\hline 0.01 & 0.03 & 48 \\
\hline-0.94 & 0.36 & 48 \\
\hline-0.62 & 0.36 & 48 \\
\hline-1.29 & 0.36 & 48 \\
\hline 0.36 & 0.36 & 48 \\
\hline 0.68 & 0.36 & 48 \\
\hline-0.32 & 0.36 & 48 \\
\hline
\end{tabular}

\begin{tabular}{c}
\hline T-Value \\
\hline-7.05 \\
-7.88 \\
-0.2 \\
-6.86 \\
-7.7 \\
0.83 \\
-8.14 \\
-9.88 \\
-1.75 \\
-6.41 \\
-8.15 \\
1.73 \\
-8.87 \\
-10.43 \\
-1.3 \\
-7.58 \\
-9.15 \\
1.55 \\
-5.11 \\
-2.66 \\
-1.14 \\
-3.98 \\
-1.52 \\
-2.45 \\
-4.07 \\
-4.47 \\
-1.25 \\
-2.83 \\
-3.23 \\
0.4 \\
-2.59 \\
-1.7 \\
-3.58 \\
0.99 \\
1.88 \\
-0.89 \\
\hline \\
\hline
\end{tabular}

\begin{tabular}{l}
\hline \multicolumn{1}{c}{$\operatorname{Pr}>|t|$} \\
\hline$<.0001$ \\
$<.0001$ \\
0.84 \\
$<.0001$
\end{tabular}

$<.0001$

$<.0001$

0.437

$<.0001$

$<.0001$

0.129

$<.0001$

$<.0001$

0.129

$<.0001$

$<.0001$

0.247

$<.0001$

$<.0001$

0.169

$<.0001$

0.019

0.301

0.001

0.173

0.029

$<.0001$

$<.0001$

0.263

0.013

0.004

0.709

0.022

0.132

0.002

0.37

0.105

0.413

$\triangle \mathrm{LSM}$, differences of least squares means; AG, acyl ghrelin; BP, blood pressure; Com, combined AG +DAG; DAG, desacyl ghrelin; HR, heart rate; MAP, mean arterial pressure; RR, respiratory rate; S.E.M., standard error of the mean; Temp, body surface temperature. 
Blood samples for hormone measurements were placed on ice, and plasma and serum were separated by centrifugation within $1 \mathrm{~h}$ and stored at $-80^{\circ} \mathrm{C}$ until assay. Blood for $A G$ and DAG measurements was collected directly into $4 \mathrm{mM}$ 4-(2-amionoethyl)benzenesulfonyl fluoride hydrochloride (AEBSF), a protease and esterase inhibitor, and $200 \mu \mathrm{L} 1 \mathrm{M} \mathrm{HCl}$ was added to every milliliter of plasma.

After withdrawal of fasting blood samples, a bolus dose of synthetic human AG (CS Bio, Menlo Park, CA, USA; $0.28 \mu \mathrm{g} / \mathrm{kg}$ ), synthetic human DAG (CS Bio; $1.1 \mu \mathrm{g} / \mathrm{kg}$ ), combined AG+DAG or saline was given at time 0 , followed by a continuous IV infusion of AG at $1.0 \mu \mathrm{g} / \mathrm{kg} / \mathrm{h}$, DAG at $4.0 \mu \mathrm{g} / \mathrm{kg} / \mathrm{h}$, combined AG $(1.0 \mu \mathrm{g} /$ $\mathrm{kg} / \mathrm{h})$ and DAG $(4.0 \mu \mathrm{g} / \mathrm{kg} / \mathrm{h})$ or saline respectively, for a total of $210 \mathrm{~min}$. A higher concentration of DAG was used in the study to mimic the ratio of AG:DAG found in healthy humans in the fed state (3). Based on the pharmacokinetic data from previous studies (27), ghrelin levels in the circulation were expected to reach a steady state within $30 \mathrm{~min}$ of ghrelin infusion.

After $30 \mathrm{~min}$ of peptide/saline infusion, an IV bolus of $50 \%$ dextrose solution $\left(11.4 \mathrm{~g} / \mathrm{m}^{2}\right.$ body surface area) was given as the commencement of an insulin-modified frequently sampled intravenous glucose tolerance test (IVGTT) (28). Subsequently, regular insulin (0.025 units/ $\mathrm{kg}$ body wt) was infused intravenously over $5 \mathrm{~min}$, starting $20 \mathrm{~min}$ after the glucose injection. AG and DAG levels were measured at $-15,0,5,15,25,30,60,90$, 150 and $210 \mathrm{~min}$; norepinephrine (NE) and epinephrine (Epi) levels were measured at $-1,29$ and $30 \mathrm{~min}$ and renin and aldosterone levels were measured at $-15,29$, $46,60,90$ and $210 \mathrm{~min}$.

\section{Assays}

Plasma NE and Epi were measured by high-performance liquid chromatography with electrochemical detection. Plasma was absorbed onto alumina at a $\mathrm{pH}$ of 8.6, catecholamines eluted with dilute perchloric acid and auto-injected onto a c18 reversed-phase column. An internal standard (dihydroxybenzylamine; DHBA) was included with each extraction to monitor recovery and standard curves for NE and Epi. Results were quantified through a chromatography data station $(29,30)$. Plasma aldosterone and plasma active renin were measured in 10 of the 17 subjects by automated chemiluminescence immunoassays (LIAISON, DiaSorin, Saluggia, Italy) as previously described $(31,32)$.

\section{Statistical analysis}

Differences in baseline values of the outcome variables between treatment groups were assessed with KruskalWallis test using GraphPad Prism v.6. Data were analyzed using mixed-model regression where each of the main outcomes of interest (sBP, dBP, MAP, HR, RR, Temp) was modeled as a function of treatment group, time, the interaction between time and group and the baseline
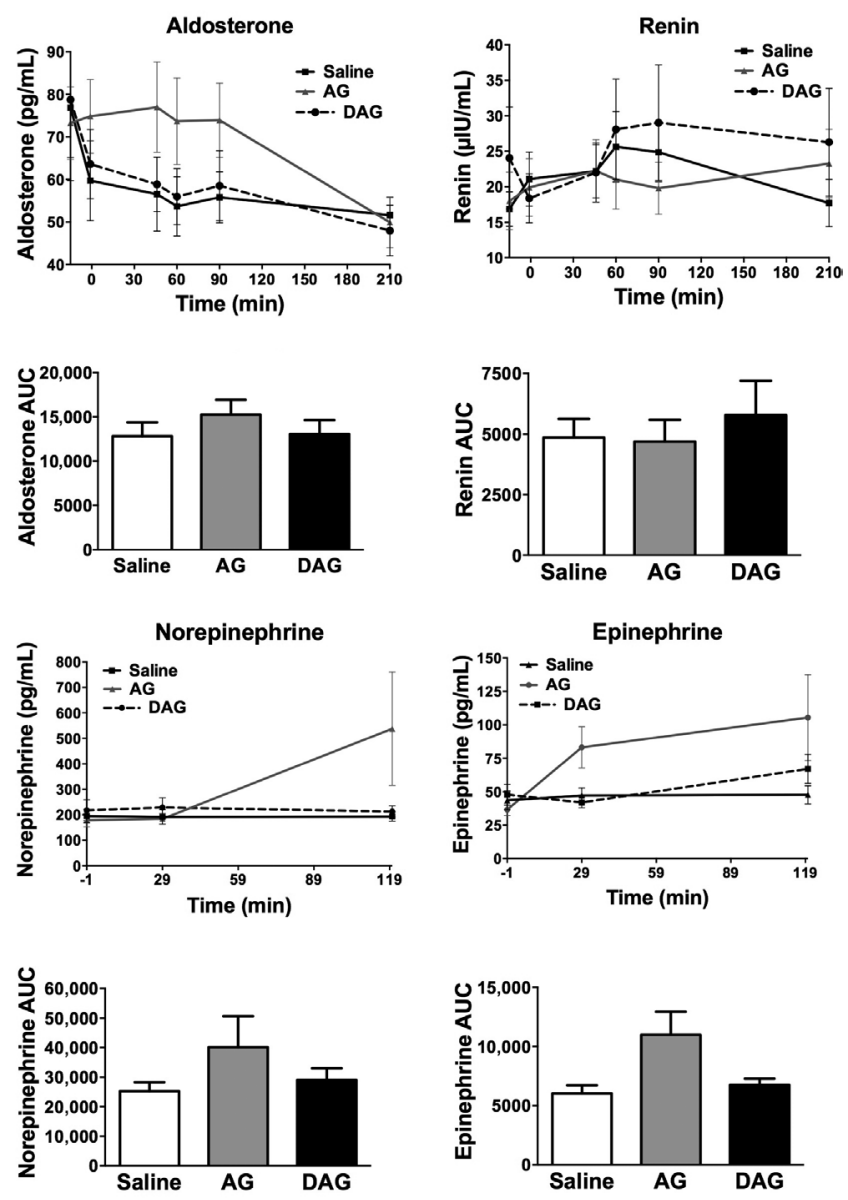

\section{Figure 2}

Study 1: Effects of AG and DAG on catecholamines, renin and aldosterone. Plasma aldosterone (pg/mL; Fig. 2A), renin ( $\mu \mathrm{IU} /$ $\mathrm{mL}$; Fig. 2B), norepinephrine (NE in pg/mL; Fig. $2 \mathrm{C}$ ) and epinephrine (Epi in pg/mL; Fig. 2D) concentrations during a 210-min infusion of saline, acyl ghrelin (AG), desacyl ghrelin (DAG) or combined AG + DAG in 10 healthy men and women. The NE and Epi concentrations were only assayed until the 120-min time point. An intravenous glucose tolerance test (IVGTT) was also performed between 30 and $210 \mathrm{~min}$ after the peptide infusions began. The area under the curve (AUC) is shown for NE, Epi, renin and aldosterone. 
outcome measure (at time 0). Both the difference between treatment groups and the difference across time were tested using this model. Comparisons between treatment groups were assessed using differences of least squares means (LSM) analysis with $P$ values adjusted for multiple comparisons for using the Tukey-Kramer method as implemented in the SAS software. To assess the effect of ghrelin infusions on the levels of catecholamines, aldosterone and renin, areas under the curve (AUC) were calculated using the trapezoid method for each of these hormones and compared using the repeated measures oneway ANOVA with adjustment of multiple comparisons. All data analysis except for the baseline comparison was performed using SAS (Cary, NC, USA). Results are expressed as mean \pm s.E.M. unless otherwise noted.

\section{Results}

\section{Subject characteristics}

Seventeen healthy subjects ( 9 men and 8 women) aged 26.6 years (SD 8.3) with BMI of $24 \mathrm{~kg} / \mathrm{m}^{2}$ (SD 3.8) completed the study; 3 other subjects enrolled but did not complete all the infusions and were not included in the analysis. Physiologic parameters (sBP, dBP, MAP, HR, Temp and RR) and hormone levels measured at baseline (before the start of infusions) did not differ within subjects on the 4 study days.

\section{Hemodynamic and autonomic effects of AG and DAG}

Compared to saline control, continuous AG as well as the combined AG + DAG infusion decreased sBP $(\triangle \mathrm{LSM}-3.84$, $P<0.0001$ and $\Delta \mathrm{LSM}-3.73, \quad P<0.0001$ respectively),
dBP $(\Delta$ LSM $-3.10, P<0.0001$ and $\Delta$ LSM $-2.44, P<0.0001$ respectively) and MAP ( $\triangle \mathrm{LSM}-3.35, P<0.0001$ and $\Delta \mathrm{LSM}$ $-2.86, P<0.0001$ respectively) for the duration of the study (Fig. $1 \mathrm{~A}, \mathrm{~B}, \mathrm{C}$ and Table 1). In contrast, DAG alone had no effect on sBP ( $\triangle \mathrm{LSM} 0.45, P=0.437)$, dBP $(\triangle \mathrm{LSM} 0.66$ saline vs DAG, $P=0.129$ ), or MAP ( $\triangle$ LSM $0.59, P=0.169$ ) compared to saline (Table 1). AG and combined AG + DAG infusion also decreased HR $(\triangle \mathrm{LSM}-3.0, P<0.0001$ and $\triangle \mathrm{LSM}-2.33, P=0.0001$ respectively) when compared to saline control (Fig. 1D and Table 1). DAG infusion led to smaller but significant decrease in HR ( $\triangle \mathrm{LSM}-1.44$ saline vs DAG, $P=0.029$ Fig. $1 \mathrm{D}$ and Table 1$)$.

$A G$ and combined $A G+D A G$ induced a decrease in body surface temperature compared to the saline control $(\Delta \mathrm{LSM}-0.11, \quad P<0.0001$ and $\Delta \mathrm{LSM}-0.08, \quad P=0.013$ respectively), whereas DAG alone had no significant effect on temperature ( $\triangle \mathrm{LSM}-0.01, P=0.709)$ (Fig. $1 \mathrm{E}$ and Table 1). AG led to a modest decrease in RR compared to saline ( $\triangle \mathrm{LSM}-0.94, P=0.022$ ) (Fig. $1 \mathrm{~F}$ and Table 1 ). DAG alone and combination $A G+D A G$ had no effect on RR compared to saline (Fig. 1F and Table 1).

Significant differences for BP and Temp, but not HR or $\mathrm{RR}$, were observed between the combined treatment and DAG treatment (Table 1).

\section{Effects of AG and DAG on BP-modulating hormone levels}

Although renin levels were not different between all drug treatment groups compared to saline, plasma aldosterone level was significantly higher during AG infusion compared to saline and DAG treatment (AG vs saline $\Delta$ LSM 30.2, $P<0.0001$, AG vs DAG $\Delta$ LSM 25.4, $P=0.0002$ ) (Fig. 2 and Table 2). AG, DAG and

Table 2 Comparison of hormone concentrations in response to AG and DAG.

\begin{tabular}{|c|c|c|c|c|c|c|c|}
\hline & Treatment & Comparison & $\Delta$ LSM & S.E.M. & DF & T-Value & $\operatorname{Pr}>|t|$ \\
\hline \multirow[t]{3}{*}{ Aldosterone } & AG & Saline & 30.242 & 5.60 & 16 & 5.40 & $<.0001$ \\
\hline & & DAG & 25.440 & 5.20 & 16 & 4.89 & 0.0002 \\
\hline & DAG & Saline & 4.802 & 5.59 & 16 & 0.86 & 0.4028 \\
\hline \multirow[t]{3}{*}{ Renin } & $\mathrm{AG}$ & Saline & 2.165 & 2.39 & 16 & 0.91 & 0.3783 \\
\hline & & DAG & 3.960 & 2.20 & 16 & 1.80 & 0.0910 \\
\hline & DAG & Saline & -1.795 & 2.39 & 16 & -0.75 & 0.4642 \\
\hline \multirow[t]{3}{*}{ NE } & AG & Saline & 32.543 & 81.58 & 18 & 0.40 & 0.6946 \\
\hline & & DAG & 95.668 & 110.69 & 18 & 0.86 & 0.3988 \\
\hline & DAG & Saline & 63.123 & 81.30 & 18 & 0.78 & 0.4476 \\
\hline \multirow[t]{3}{*}{ Epi } & AG & Saline & 18.576 & 16.67 & 18 & 1.11 & 0.2799 \\
\hline & & DAG & 26.571 & 16.52 & 18 & 1.61 & 0.1252 \\
\hline & DAG & Saline & 7.995 & 16.60 & 18 & 0.48 & 0.6360 \\
\hline
\end{tabular}

$\triangle \mathrm{LSM}$, differences of least squares means; AG, acyl ghrelin; Com, combined AG + DAG; DAG, desacyl ghrelin; DF, degrees of freedom; Epi, epinephrine; $\mathrm{NE}$, norepinephrine; S.E.M., standard error of the mean. 
saline infusions did not affect plasma NE and Epi levels (Fig. 2 and Table 2). AUC values for NE, Epi, renin and aldosterone after ghrelin and saline infusions are shown in Fig. 2E, F, G and H. Although neither were significant, NE and Epi AUC values show a trend to be increased by AG compared to DAG and saline.

\section{Discussion}

The role of AG in the regulation of cardiovascular function has been extensively studied, but the precise mechanism for its BP-lowering effect has not been elucidated. DAG has been reported to have GHSR-independent effects on the CV system in rodents that are largely protective $(33,34)$, but its effect in humans is not well understood. Our study is novel in its use of a DAG infusion to explore the direct effect of this hormone on CV tone. We also investigated the role of $\mathrm{AG}$ and $\mathrm{DAG}$ on autonomic parameters beyond $\mathrm{BP}$ and HR, which have not been previously studied in humans. Finally, we attempted to determine the hormonal mechanisms through which DAG and AG could exert their cardiovascular effects. Interestingly, the DAG infusion had no effect on any autonomic parameter except HR. We found that AG infusion led to a decrease in $\mathrm{sBP}, \mathrm{dBP}$ and MAP, as expected, with new findings that it also lowered HR, RR and Temp. The BP-lowering effect of AG was unaffected by the coadministration of DAG. Thus, our findings imply that the effect of AG on the cardiovascular system is likely dependent on GHSR receptor activation.

Several clinical studies have demonstrated decreased arterial pressure after AG is given as IV bolus or infusion $(19,35,36)$. Our study, novel in its continuous monitoring of systemic BP and HR over a 3-h infusion period, supports these previous findings as AG infusion lowered both sBP and dBP. However, the effect was modest. The average decreases in $\mathrm{sBP}$ and $\mathrm{dBP}$ from baseline were $5.2 \pm 1.7$ and $5.9 \pm 1.5 \mathrm{mmHg}$ respectively. We found a similarly modest, but significant decrease in HR that has been noted in some, but not all, human studies as well as rodent studies $(35,37)$. The discrepancies in HR effects between studies may be due to differences in AG doses or mode of administration. However, in reviewing studies that found no changes in HR despite decreased BP, we do note a nonsignificant trend of lower heart rate with $\operatorname{AG}(18,19)$.

The precise mechanism(s) by which AG lowers blood pressure is not known, but the possibilities include (1) central effects on the sympathetic and parasympathetic nervous system (22, 37), (2) peripheral effects through direct action on blood vessels $(15,20)$ and/or (3) hormonally mediated effects on either of these systems. AG can cross the blood-brain barrier (38), and the ghrelin receptor (GHSR) is present in the autonomic preganglionic neurons (16) and the nucleus tractus solitarius (NTS) (22), a brain region that regulates autonomic outflow. Direct ghrelin injection into the NTS has been shown to decrease HR and MAP in rodents (22). Peripheral ghrelin administration can suppress cardiac sympathetic nervous activity, increase parasympathetic activity and prevent early left ventricular remodeling in rats after myocardial infarction (39). Similarly in humans, peripheral AG bolus injection decreases parameters of sympathetic nervous activity while increasing measures of parasympathetic nervous activity during Holter monitoring (35). Our findings of simultaneous decreases in BP and HR suggest that AG decreases sympathetic and/or increases parasympathetic outflow to the CV system. The negative effect of AG on catecholamine secretion observed in the current study could be due to the insufficient sample size. With the decrease in $\mathrm{BP}$, we would expect a temporary rise in catecholamine levels; however, this effect may be offset by decreased sympathetic tone, which should lower catecholamines. Although increased levels of Epi have been demonstrated by studies using AG intravenous boluses $(19,36)$, this neutral effect of AG on Epi has been found previously in healthy humans given AG infusions at doses similar to those used in our study (7). As for the second hypothesis, although AG is also reported to act peripherally on the vasculature by decreasing tone and peripheral vascular resistance $(15,20)$, we would expect this effect to result in increased HR along with decreased BP instead of the decreased HR that we observed.

Not much is known about the effect of ghrelin on body temperature or respiratory drive in humans. In rodents, intracerebroventricular (ICV) injection of AG (40) and DAG (41) decreases core body temperature. This effect could be mediated through decreased brown adipose tissue sympathetic nerve activity resulting in decreased thermogenesis (42) and/or activation of the hypothalamic thermoregulatory center (43). Furthermore, neuronal deletion of GHSR increases energy expenditure, locomotor activity and thermogenesis (44). The physiological significance of the observed effect of $A G$ on Temp needs further investigation. No studies have assessed the effects of ghrelin on RR. GHSR is expressed in brain centers that control respiration (i.e. medulla oblongata and pons) (45), and more relevant to our other findings, 
respiration is controlled by the autonomic nervous system. We speculate that the decreased RR with AG at least partly results from decreased sympathetic outflow or increased parasympathetic tone.

We also examined hormonal mechanisms through which AG or DAG could affect BP and HR. Changes in catecholamine levels and the renin-angiotensinaldosterone system in response to sympathetic signaling are key mediators of short-term cardiovascular homeostasis. Previous studies have shown increased levels of Epi, ACTH and cortisol with AG administration in humans $(19,36)$. However, we neither observe significant changes in plasma Epi with AG infusion nor did we see changes in NE or renin levels. DAG infusion did not affect any hormone levels in our study, which is consistent with previous findings that DAG did not alter ACTH, GH or prolactin levels in humans (46).

However, we did observe an increase in aldosterone levels with AG infusion, a finding that has multiple potential explanations. AG is known to stimulate the release of pituitary hormones including growth hormone, prolactin and ACTH (46). We have also reported previously that AG, but not DAG, stimulates cortisol secretion (11). Although ACTH levels were not measured during this study, the elevated cortisol levels support an increase in ACTH, which may have stimulated aldosterone release as well. Consistent with this hypothesis, although AG fails to stimulate aldosterone secretion from freshly isolated adrenocortical cells (47), GOAT inhibition has been shown to decrease plasma ACTH, aldosterone and corticosterone levels in vivo in rats (48).

Alternatively, decreased preload resulting from the AG infusion may have decreased levels of the natriuretic peptides, atrial natriuretic peptide (ANP) and brain natriuretic peptide (BNP). The natriuretic peptides are important inhibitors of aldosterone secretion (49); thus, lower levels may have resulted in increased aldosterone. Because the natriuretic peptides can also inhibit catecholamine release as well as renin (49), we might have expected to see similar rises in these hormones. However, a study of salt-induced hypertension in rats also found no effect of chronic ghrelin administration on renin or urine catecholamine levels, despite improved BP in the ghrelin-treated group (50). Although aldosterone levels were not measured in that study, ghrelin treatment did significantly decrease ANP mRNA expression in the myocardium of the high salt group (50). Additional work is needed to define the effects of AG-related BP changes on natriuretic peptide and aldosterone levels.
With a clinical trial reporting beneficial effects of DAG on glucose metabolism distinct from the actions of AG (13), we sought to explore whether DAG could also exert GHSR-independent effects on BP. To our knowledge, prior investigations assessing the $\mathrm{CV}$ effects of DAG have been limited to animal models and in vitro settings. DAG was comparable to AG in reversing endothelin-1-induced vasoconstriction in isolated human coronary arteries (15) and decreasing MAP and HR when administered centrally to the NTS in rats (51). More recently, lower levels of DAG have been associated with an increased risk of $\mathrm{CV}$ events (26) in older hypertensive humans as well as increased BP in men with hypertension (25). We show that in humans, peripheral DAG infusion did not alter systemic BP, RR or Temp acutely or counteract the effects of AG. Therefore, the observed ghrelin effects on the CV system are likely to be GHSR dependent. Interestingly, DAG infusion alone did lead to a modest decrease in HR compared to saline control with no significant changes in BP. This isolated bradycardic effect of DAG has not been seen previously in humans and could be mediated by DAG-specific receptors on cardiomyocytes, which have been described in mice (52). Future studies are needed to confirm this finding.

There are limitations of our study. First, BP, HR, RR and Temp measurements were obtained as part of a study that involved an insulin-modified frequently sampled IVGTT. The IV glucose bolus $\left(11.4 \mathrm{~g} / \mathrm{m}^{2}\right)$ and/or insulin infusion (0.025 units $/ \mathrm{kg}$ ) could have affected our CV parameters. However, as the IVGTT occurred on all study days, any confounding effects should have been equivalent on all days. Secondly, the hormonal measures (i.e. Epi, NE, renin and aldosterone) were only obtained in 10 of the 17 participants. Therefore, as mentioned previously, we cannot exclude a type II error in our negative findings on catecholamine or renin secretion.

Overall, our study confirms past findings that AG infusion decreases systemic BP in healthy humans and yields additional findings of decreases in $\mathrm{HR}$, RR, and Temp. We believe the most likely explanation for these CV effects is through CNS actions of AG to depress sympathetic tone and/or stimulate parasympathetic activity. Furthermore, we report the novel finding that continuous DAG infusion in humans does not significantly change BP nor does it counteract the CV effects of AG. However, DAG did mildly lower HR, which suggests a GHSR-independent mechanism and may have clinical implications, as GOAT inhibitors and DAG mimetics are being actively pursued as therapeutic options for type 2 diabetes and obesity. These ongoing trials highlight the importance of understanding the effect of ghrelin on the CV system. 


\section{Declaration of interest}

The authors declare that there is no conflict of interest that could be perceived as prejudicing the impartiality of the research reported.

\section{Funding}

Funding for this research is provided by NIH/NIDDK (R03DK89090 and R01DK097550 to J T and R0157900 to D D) and supported in part by USPHS grant \#UL1 RR026314 from the National Center for Research Resources, NIH. L P was supported by NIH training grants (5T32Al007217-33 and 4T32HD043029-14).

\section{Author contribution statement}

C Z wrote the manuscript and contributed to the discussion. M B contributed to the assay performance, the discussion and editing of the manuscript. M A analyzed the data. L P contributed to the discussion and reviewed/edited the manuscript. D D contributed to the discussion and reviewed/edited the manuscript. M T contributed to the discussion and reviewed the manuscript. J $\mathrm{T}$ designed the study, collected the data and reviewed/edited the manuscript.

\section{References}

1 Kojima M, Hosoda H, Date Y, Nakazato M, Matsuo H \& Kangawa K. Ghrelin is a growth-hormone-releasing acylated peptide from stomach. Nature $1999 \mathbf{4 0 2} 656-660$. (doi:10.1038/45230)

2 Müller TD, Nogueiras R, Andermann ML, Andrews ZB, Anker SD, Argente J, Batterham RL, Benoit SC, Bowers CY, Broglio F et al. Ghrelin. Molecular Metabolism 20154 437-460. (doi:10.1016/j. molmet.2015.03.005)

3 Liu J, Prudom CE, Nass R, Pezzoli SS, Oliveri MC, Johnson ML, Veldhuis P, Gordon DA, Howard AD, Witcher DR et al. Novel ghrelin assays provide evidence for independent regulation of ghrelin acylation and secretion in healthy young men. Journal of Clinical Endocrinology and Metabolism 200893 1980-1987. (doi:10.1210/ jc.2007-2235)

4 Cummings DE, Frayo RS, Marmonier C, Aubert R \& Chapelot D. Plasma ghrelin levels and hunger scores in humans initiating meals voluntarily without time- and food-related cues. American Journal of Physiology Endocrinology and Metabolism 2004287 E297-E304. (doi:10.1152/ajpendo.00582.2003)

5 Miki K, Maekura R, Nagaya N, Nakazato M, Kimura H, Murakami S, Ohnishi S, Hiraga T, Miki M, Kitada S et al. Ghrelin treatment of cachectic patients with chronic obstructive pulmonary disease: a multicenter, randomized, double-blind, placebo-controlled trial. PLoS ONE 20127 e35708. (doi:10.1371/journal.pone.0035708)

6 Strasser F, Lutz TA, Maeder MT, Thuerlimann B, Bueche D, Tschop M, Kaufmann K, Holst B, Brandle M, von Moos R et al. Safety, tolerability and pharmacokinetics of intravenous ghrelin for cancer-related anorexia/cachexia: a randomised, placebo-controlled, double-blind, double-crossover study. British Journal of Cancer 200898 300-308. (doi:10.1038/sj.bjc.6604148)

7 Tong J, Prigeon RL, Davis HW, Bidlingmaier M, Kahn SE, Cummings DE, Tschop MH \& D'Alessio D. Ghrelin suppresses glucose-stimulated insulin secretion and deteriorates glucose tolerance in healthy humans. Diabetes 201059 2145-2151. (doi:10.2337/db10-0504)

8 Tong J, Davis HW, Gastaldelli A \& D'Alessio D. Ghrelin impairs prandial glucose tolerance and insulin secretion in healthy humans despite increasing GLP-1. Journal of Clinical Endocrinology and Metabolism 2016101 2405-2414. (doi:10.1210/jc.2015-4154)
9 Barnett BP, Hwang Y, Taylor MS, Kirchner H, Pfluger PT, Bernard V, Lin YY, Bowers EM, Mukherjee C, Song WJ et al. Glucose and weight control in mice with a designed ghrelin O-acyltransferase inhibitor. Science 2010330 1689-1692. (doi:10.1126/ science.1196154)

10 Gauna C, Kiewiet RM, Janssen JA, van de Zande B, Delhanty PJ, Ghigo E, Hofland LJ, Themmen AP \& van der Lely AJ. Unacylated ghrelin acts as a potent insulin secretagogue in glucose-stimulated conditions. American Journal of Physiology Endocrinology and Metabolism 2007293 E697-E704. (doi:10.1152/ ajpendo.00219.2007)

11 Tong J, Davis HW, Summer S, Benoit SC, Haque A, Bidlingmaier M, Tschoep MH \& D'Alessio D. Acute administration of unacylated ghrelin has no effect on basal or stimulated insulin secretion in healthy humans. Diabetes 201463 2309-2319. (doi:10.2337/db131598)

12 Benso A, St-Pierre DH, Prodam F, Gramaglia E, Granata R, van der Lely AJ, Ghigo E \& Broglio F. Metabolic effects of overnight continuous infusion of unacylated ghrelin in humans. European Journal of Endocrinology 2012166 911-916. (doi:10.1530/EJE-110982)

13 Allas S, Delale T, Ngo N, Julien M, Sahakian P, Ritter J, Abribat T \& van der Lely AJ. Safety, tolerability, pharmacokinetics and pharmacodynamics of AZP-531, a first-in-class analogue of unacylated ghrelin (UAG), in healthy, overweight/obese, and type 2 diabetes subjects. Diabetes, Obesity and Metabolism 201618 868-874. (doi:10.1111/dom.12675)

14 Virdis A, Lerman LO, Regoli F, Ghiadoni L, Lerman A \& Taddei S. Human ghrelin: a gastric hormone with cardiovascular properties. Current Pharmaceutical Design 201622 52-58. (doi:10.2174/13816128 22666151119144458)

15 Kleinz MJ, Maguire JJ, Skepper JN \& Davenport AP. Functional and immunocytochemical evidence for a role of ghrelin and des-octanoyl ghrelin in the regulation of vascular tone in man. Cardiovascular Research 200669 227-235. (doi:10.1016/j. cardiores.2005.09.001)

16 Ferens DM, Yin L, Bron R, Hunne B, Ohashi-Doi K, Kitchener PD, Sanger GJ, Witherington J, Shimizu Y \& Furness JB. Functional and in situ hybridization evidence that preganglionic sympathetic vasoconstrictor neurons express ghrelin receptors. Neuroscience 2010 166 671-679. (doi:10.1016/j.neuroscience.2010.01.001)

17 Lim CT, Kola B, Grossman A \& Korbonits M. The expression of ghrelin O-acyltransferase (GOAT) in human tissues. Endocrine Journal 201158 707-710. (doi:10.1507/endocrj.K11E-117)

18 Nagaya N, Miyatake K, Uematsu M, Oya H, Shimizu W, Hosoda H, Kojima M, Nakanishi N, Mori H \& Kangawa K. Hemodynamic, renal, and hormonal effects of ghrelin infusion in patients with chronic heart failure. Journal of Clinical Endocrinology and Metabolism 200186 5854-5859. (doi:10.1210/jcem.86.12.8115)

19 Nagaya N, Kojima M, Uematsu M, Yamagishi M, Hosoda H, Oya H, Hayashi Y \& Kangawa K. Hemodynamic and hormonal effects of human ghrelin in healthy volunteers. American Journal of Physiology Regulatory, Integrative and Comparative Physiology 2001280 R1483-R1487.

20 Wiley KE \& Davenport AP. Comparison of vasodilators in human internal mammary artery: ghrelin is a potent physiological antagonist of endothelin-1. British Journal of Pharmacology 2002136 1146-1152. (doi:10.1038/sj.bjp.0704815)

21 Iantorno M, Chen H, Kim JA, Tesauro M, Lauro D, Cardillo C \& Quon MJ. Ghrelin has novel vascular actions that mimic PI 3-kinase-dependent actions of insulin to stimulate production of NO from endothelial cells. American Journal of Physiology Endocrinology and Metabolism 2007292 E756-E764. (doi:10.1152/ ajpendo.00570.2006)

22 Lin Y, Matsumura K, Fukuhara M, Kagiyama S, Fujii K \& Iida M. Ghrelin acts at the nucleus of the solitary tract to decrease 
arterial pressure in rats. Hypertension 200443 977-982. (doi:10.1161/01.HYP.0000122803.91559.55)

23 Heppner KM \& Tong J. Mechanisms in endocrinology: regulation of glucose metabolism by the ghrelin system: multiple players and multiple actions. European Journal of Endocrinology 2014171 R21-R32. (doi:10.1530/EJE-14-0183)

24 Moazed B, Quest D \& Gopalakrishnan V. Des-acyl ghrelin fragments evoke endothelium-dependent vasodilatation of rat mesenteric vascular bed via activation of potassium channels. European Journal of Pharmacology 2009604 79-86. (doi:10.1016/j. ejphar.2008.10.032)

25 Gibas-Dorna M, Nowak D, Piatek J, Pupek-Musialik D, Krauss H \& Kopczynski P. Plasma ghrelin and interleukin-6 levels correlate with body mass index and arterial blood pressure in males with essential hypertension. Journal of Physiology and Pharmacology 201566 367-372.

26 Yano Y, Nakazato M, Toshinai K, Inokuchi T, Matsuda S, Hidaka T, Hayakawa M, Kangawa K, Shimada K \& Kario K. Circulating des-acyl ghrelin improves cardiovascular risk prediction in older hypertensive patients. American Journal of Hypertension 201427 727-733. (doi:10.1093/ajh/hpt232)

27 Tong J, Dave N, Mugundu GM, Davis HW, Gaylinn BD, Thorner MO, Tschop MH, D'Alessio D \& Desai PB. The pharmacokinetics of acyl, des-acyl, and total ghrelin in healthy human subjects. European Journal of Endocrinology $2013 \mathbf{1 6 8}$ 821-828. (doi:10.1530/EJE-13-0072)

28 Utzschneider KM, Tong J, Montgomery B, Udayasankar J, Gerchman F, Marcovina SM, Watson CE, Ligueros-Saylan MA, Foley JE, Holst JJ et al. The dipeptidyl peptidase-4 inhibitor vildagliptin improves beta-cell function and insulin sensitivity in subjects with impaired fasting glucose. Diabetes Care 200831 108-113. (doi:10.2337/dc07-1441)

29 Goldstein DS, Feuerstein G, Izzo JL Jr, Kopin IJ \& Keiser HR. Validity and reliability of liquid chromatography with electrochemical detection for measuring plasma levels of norepinephrine and epinephrine in man. Life Sciences 198128 467-475. (doi:10.1016/0024-3205(81)90139-9)

30 Anton AH \& Sayre DF. A study of the factors affecting the aluminum oxide-trihydroxyindole procedure for the analysis of catecholamines. Journal of Pharmacology and Experimental Therapeutics 1962138 360-375.

31 Manolopoulou J, Fischer E, Dietz A, Diederich S, Holmes D, Junnila R, Grimminger P, Reincke M, Morganti A \& Bidlingmaier M. Clinical validation for the aldosteroneto-renin ratio and aldosterone suppression testing using simultaneous fully automated chemiluminescence immunoassays. Journal of Hypertension 201533 2500-2511. (doi:10.1097/ HJH.0000000000000727)

32 Morganti A \& European study group for the validation of DiaSorin LDRA. A comparative study on inter and intralaboratory reproducibility of renin measurement with a conventional enzymatic method and a new chemiluminescent assay of immunoreactive renin. Journal of Hypertension 201028 1307-1312.

33 Pei XM, Yung BY, Yip SP, Chan LW, Wong CS, Ying M \& Siu PM. Protective effects of desacyl ghrelin on diabetic cardiomyopathy. Acta Diabetologica 201552 293-306. (doi:10.1007/s00592-0140637-4)

34 Pei XM, Yung BY, Yip SP, Ying M, Benzie IF \& Siu PM. Desacyl ghrelin prevents doxorubicin-induced myocardial fibrosis and apoptosis via the GHSR-independent pathway. American Journal of Physiology Endocrinology and Metabolism 2014306 E311-E323. (doi:10.1152/ ajpendo.00123.2013)

35 Soeki T, Koshiba K, Niki T, Kusunose K, Yamaguchi K, Yamada H, Wakatsuki T, Shimabukuro M, Minakuchi K, Kishimoto I et al. Effect of ghrelin on autonomic activity in healthy volunteers. Peptides 2014 62 1-5. (doi:10.1016/j.peptides.2014.09.015)
36 Krapalis AF, Reiter J, Machleidt F, Iwen KA, Dodt C, Lehnert H \& Sayk F. Ghrelin modulates baroreflex-regulation of sympathetic vasomotor tone in healthy humans. American Journal of Physiology Regulatory, Integrative and Comparative Physiology 2012302 R1305-R1312. (doi:10.1152/ajpregu.00663.2011)

37 Matsumura K, Tsuchihashi T, Fujii K, Abe I \& Iida M. Central ghrelin modulates sympathetic activity in conscious rabbits. Hypertension 200240 694-699. (doi:10.1161/01. HYP.0000035395.51441.10)

38 Banks WA, Tschop M, Robinson SM \& Heiman ML. Extent and direction of ghrelin transport across the blood-brain barrier is determined by its unique primary structure. Journal of Pharmacology and Experimental Therapeutics 2002302 822-827. (doi:10.1124/ jpet.102.034827)

39 Soeki T, Kishimoto I, Schwenke DO, Tokudome T, Horio T, Yoshida M, Hosoda H \& Kangawa K. Ghrelin suppresses cardiac sympathetic activity and prevents early left ventricular remodeling in rats with myocardial infarction. American Journal of Physiology Heart and Circulatory Physiology 2008294 H426-H432. (doi:10.1152/ ajpheart.00643.2007)

40 Lawrence CB, Snape AC, Baudoin FM \& Luckman SM. Acute central ghrelin and GH secretagogues induce feeding and activate brain appetite centers. Endocrinology 2002143 155-162. (doi:10.1210/ endo.143.1.8561)

41 Inoue Y, Nakahara K, Maruyama K, Suzuki Y, Hayashi Y, Kangawa K \& Murakami N. Central and peripheral des-acyl ghrelin regulates body temperature in rats. Biochemical and Biophysical Research Communications 2013430 278-283. (doi:10.1016/j. bbrc.2012.10.137)

42 Yasuda T, Masaki T, Kakuma T \& Yoshimatsu H. Centrally administered ghrelin suppresses sympathetic nerve activity in brown adipose tissue of rats. Neuroscience Letters 2003349 75-78. (doi:10.1016/S0304-3940(03)00789-4)

43 Wiedmer P, Strasser F, Horvath TL, Blum D, Dimarchi R, Lutz T, Schurmann A, Joost HG, Tschop MH \& Tong J. Ghrelin-induced hypothermia: a physiological basis but no clinical risk. Physiology and Behavior 2011105 43-51. (doi:10.1016/j.physbeh.2011.03.027)

44 Bahn RS, Burch HB, Cooper DS, Garber JR, Greenlee MC, Klein I, Laurberg P, McDougall IR, Montori VM, Rivkees SA et al. Hyperthyroidism and other causes of thyrotoxicosis: management guidelines of the American Thyroid Association and American Association of Clinical Endocrinologists. Endocrine Practice 201117 456-520. (doi:10.4158/EP.17.3.456)

45 Zigman JM, Jones JE, Lee CE, Saper CB \& Elmquist JK. Expression of ghrelin receptor mRNA in the rat and the mouse brain. Journal of Comparative Neurology 2006494 528-548. (doi:10.1002/ cne.20823)

46 Broglio F, Gottero C, Prodam F, Gauna C, Muccioli G, Papotti M, Abribat T, Van Der Lely AJ \& Ghigo E. Non-acylated ghrelin counteracts the metabolic but not the neuroendocrine response to acylated ghrelin in humans. Journal of Clinical Endocrinology and Metabolism 200489 3062-3065. (doi:10.1210/jc.2003-031964)

47 Rucinski M, Ziolkowska A, Tyczewska M \& Malendowicz LK. Expression of prepro-ghrelin and related receptor genes in the rat adrenal gland and evidences that ghrelin exerts a potent stimulating effect on corticosterone secretion by cultured rat adrenocortical cells Peptides 200930 1448-1455. (doi:10.1016/j.peptides.2009.04.016)

48 Rucinski M, Ziolkowska A, Szyszka M, Hochol A \& Malendowicz LK. Evidence suggesting that ghrelin O-acyl transferase inhibitor acts at the hypothalamus to inhibit hypothalamo-pituitary-adrenocortical axis function in the rat. Peptides 201235 149-159. (doi:10.1016/j. peptides.2012.04.007)

49 Porzionato A, Macchi V, Rucinski M, Malendowicz LK \& De Caro R. Natriuretic peptides in the regulation of the hypothalamic-pituitaryadrenal axis. International Review of Cell and Molecular Biology 2010 280 1-39. (doi:10.1016/s1937-6448(10)80001-2) 
50 Aoki H, Nakata M, Dezaki K, Lu M, Gantulga D, Yamamoto K, Shimada K, Kario K \& Yada T. Ghrelin counteracts salt-induced hypertension via promoting diuresis and renal nitric oxide production in Dahl rats. Endocrine Journal 201360 571-581. (doi:10.1507/endocrj.EJ12-0371)

51 Tsubota Y, Owada-Makabe K, Yukawa K \& Maeda M. Hypotensive effect of des-acyl ghrelin at nucleus tractus solitarii of rat.
Neuroreport 200516 163-166. (doi:10.1097/00001756-20050208000019)

52 Lear PV, Iglesias MJ, Feijoo-Bandin S, Rodriguez-Penas D, MosqueraLeal A, Garcia-Rua V, Gualillo O, Ghe C, Arnoletti E, Muccioli G et al. Des-acyl ghrelin has specific binding sites and different metabolic effects from ghrelin in cardiomyocytes. Endocrinology 2010151 3286-3298. (doi:10.1210/en.2009-1205)

Received 16 September 2016

Revised version received 2 November 2016

Accepted 8 November 2016 